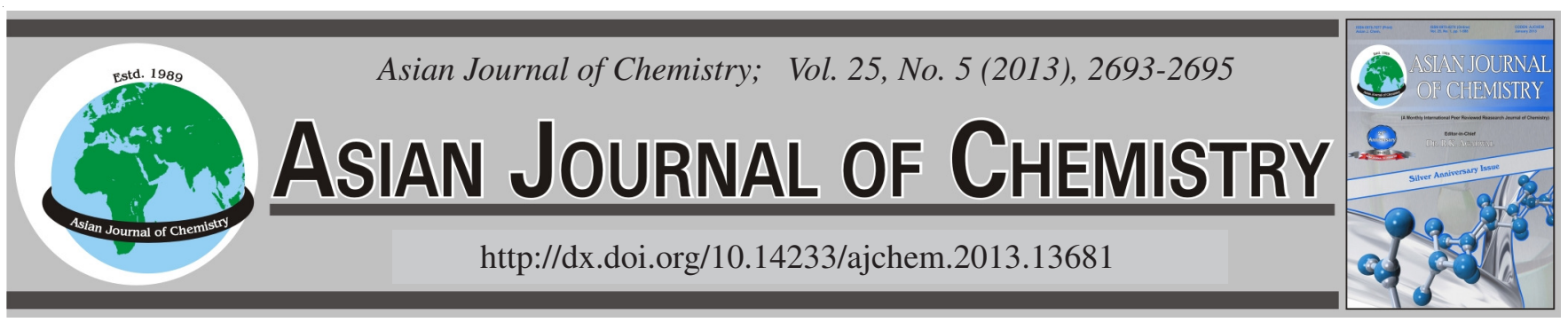

\title{
Study on Chemical Non-polar Solvent Heating by Microwave
}

\author{
Chen $\mathrm{Xu}^{1}$, Shu Jun ${ }^{2}$, Xiaoging Yang ${ }^{2, *}$, Kama Huang ${ }^{2}$ and Pukun Liu ${ }^{3}$
}

${ }^{1}$ Institute of Nuclear Science and Technology, Key Laboratory of Radiation Physics and Technology, Ministry of Education, Sichuan University, Chengdu 610064, P.R. China

${ }^{2}$ College of Electronics and Information Engineering, Sichuan University, Chengdu, 610065, P.R. China

${ }^{3}$ Key Laboratory of High Power Microwave Sources and Technologies, Institute of Electronics, Chinese Academy of Sciences, Beijing 100190, P.R. China

*Corresponding author: E-mail: yyxxqq_mail@163.com; sdill2005@126.com

(Received: 6 March 2012;

Accepted: 19 November 2012)

AJC-12431

The choice of vessel is vital for heating non-polar solvent. In this paper, non-polar solvent at container with different vessel wall sizes and
properties was heated indirectly by microwave. The uniformity of temperature was analyzed using COMSOL multiphysics under different
vessel walls during microwave heating. The results show that the temperature uniformity was influenced by the different parameters of
vessel wall sizes and properties and the uniformity of temperature can be highly improved by changing the thickness and property of
vessel wall.

\section{INTRODUCTION}

Recent reports indicated that microwave could evidently accelerate reactions and the rate enhancement factor could reach over one thousand. Most chemical reactions are sensitive to temperature; therefore using microwaves to heat reactants presents an impressive application prospect ${ }^{1,2}$. At present, in the reactions assisted and catalyzed, the majority of reaction solvents are polar in order that they are heated preferably. However, the non-polar solvents are also commonly used in a number of chemical reactions.

Although the dielectric properties of some sample are too poor to allow efficient heating by microwave radiation, the use of container that have large loss tangent values can significantly overcome this problem and enable adequate heating of the whole sample. This often provides an efficient way of using non-polar solvents for running chemical syntheses using microwave radiation. However, this method might cause heterogeneous temperature distribution in chemical syntheses. Thus, it is necessary to analyze some parameters influencing temperature uniformities using numerical calculation.

Due to the high microwave absorptive, with regard to $\mathrm{SiC}$, materials (i.e. a solvent or a reaction mixture) contained inside the container will be effectively shielded from the electromagnetic field ${ }^{3}$. The heat flow through the walls of the reaction vessel and subsequent heat exchange with the reaction mixture contained inside is exceptionally fast based on high thermal conductivity and diffusibility of $\mathrm{SiC}^{4}$.

According to the classification made by Kumbhar and Kulkarni ${ }^{5}$, the coupling of electromagnetic and thermal fields is week, due to the large difference in the time constants of the two problems ${ }^{5}$. Thus it is necessary to consider the two problems, which are the results of the electric field analysis allowing the determination of the source term for the heat diffusion equation and the analysis of the temperature distribution in the load enabling a re-evaluation of the physical constants (permittivity, loss angle, etc.), which in turn will modify the electric field distribution ${ }^{6}$. The electric energy is transformed into thermal energy and thermal energy will affect the temperature distribution. COMSOL can solve effectively the coupled electrothermal problem and it is chosen finally for this research.

\section{EXPERIMENTAL}

In this paper, the COMSOL software based on FEM is used to analyze the uniformity of temperature. The models with different vessel wall sizes and properties are separately presented to measure in detail the uniformity of temperature in the non-solvent. The physical model is shown in Fig. 1.

The problem to be solved consists of a $188 \mathrm{~mm} \times 267$ $\mathrm{mm} \times 270 \mathrm{~mm}$ metallic rectangular applicator. In this model, the inside material is non-polar carbon tetrachloride and the outer is vessel wall (such as $\mathrm{SiC}$ ). The cubage of $\mathrm{CCl}_{4}$ is $\mathrm{V}_{\mathrm{CCl}_{4}}$ 


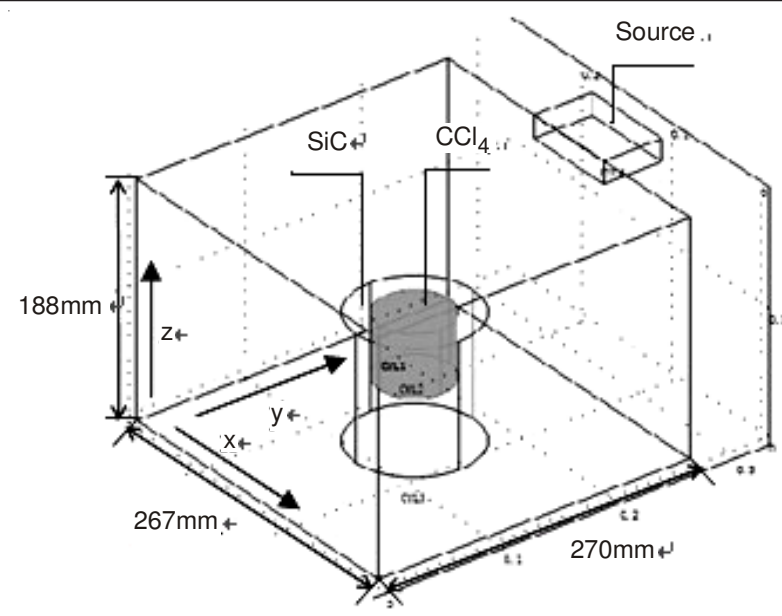

Fig. 1. Physical model

$=\pi^{*} \mathrm{r}^{2} * \mathrm{~h}$ and the cubage of $\mathrm{SiC}$ is $\mathrm{V}_{\mathrm{SIC}}=\pi^{*} \mathrm{R}^{2 *} \mathrm{~h}-\pi^{*} \mathrm{r}^{2 *} \mathrm{~h} . \mathrm{R}$ is the radius of big cylinder, $\mathrm{r}$ is the radius of small cylinder and $\mathrm{h}$ is the height of $\mathrm{CCl}_{4}$ and $\mathrm{SiC}$.

The permittivity of $\mathrm{CCl}_{4}$ was taken from reference ${ }^{7}$, which is $\varepsilon_{\mathrm{r}}=2.24-\mathrm{j} * 0.002$. The permittivity of silicon carbide changes with temperatures, so it is necessary to establish a function between the permittivity and temperature. From ${ }^{4}$, the relation between $\tan \delta$ and temperature is shown (Fig. 2).

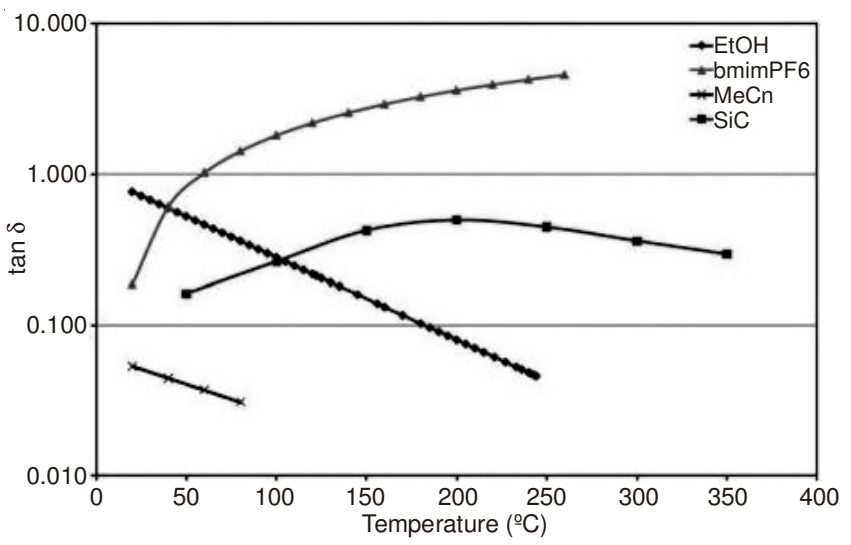

Fig. 2. Tan $\delta$ as a function of temperature for the SiC

The values of four special points from the curve of silicon carbide are analyzed in Table-1.

\begin{tabular}{ccccc}
\multicolumn{5}{c}{ TABLE-1 } \\
& LOSS Tan $\delta$ FROM THE SiC CURVE \\
\hline $\mathrm{T}\left({ }^{\circ} \mathrm{C}\right)$ & 50 & 100 & 150 & 200 \\
$\operatorname{Tan}(\delta)$ & 0.18 & 0.33 & 0.60 & 0.69 \\
\hline
\end{tabular}

According to the definition of loss tangent, $\tan \delta$ is imaginary part dividing real part of the permittivity. It is assumed that $\varepsilon_{\mathrm{r}}=\mathrm{a}-\mathrm{j} * \mathrm{~b}$, so $\tan \delta=\mathrm{b} / \mathrm{a}$. The real part of SiC permittivity, which is obtained from literature is $\mathrm{a}=6.52$ and its imaginary part, which is obtained by linear fit (Table- 1 ) is $b=-6.40786$ $+0.02347 * \mathrm{~T}$. Finally, the permittivity of $\mathrm{SiC}$ is $\varepsilon_{\mathrm{r}}=6.52-\mathrm{j} *$ $(-6.40786+0.02347 * \mathrm{~T})$. During all the computational process, the input power is $\mathrm{P}=700 \mathrm{~W}$. The microwave heating time is $\mathrm{t}=5 \mathrm{~s}$. Relative parameters which are used to solve the case are listed in Table- 2 .

\begin{tabular}{lcc}
\multicolumn{3}{c}{ TABLE-2 } \\
RELATIVE PARAMETERS \\
\hline Parameter & $\mathrm{SiC}$ & $\mathrm{CCl}_{4}$ \\
\hline Heat conduction: $\mathrm{k}(\mathrm{w} / \mathrm{m} * \mathrm{~K})$ & 20 & 0.106 \\
Density: $\rho\left(\mathrm{kg} / \mathrm{m}^{3}\right)$ & 3200 & 1595 \\
Atmospheric heat capacity: $\mathrm{C}_{\mathrm{p}}\left[\mathrm{J} /\left(\mathrm{kg}^{*}{ }^{\circ} \mathrm{C}\right)\right]$ & 170 & 854 \\
\hline
\end{tabular}

After calculation, the results such as maximum and minimum value of temperature were recorded during heating. Then the uniformities of temperature were obtained respectively by formula (1). The average temperature was achieved by formula (2).

Finally, comparing the results, the uniformity of temperature is gained.

$$
\text { Temperature uniformity }=\sqrt{\frac{\mathrm{T}_{\max }-\mathrm{T}_{\min }}{\mathrm{T}_{\max }}}
$$

where, $\mathrm{T}_{\max }$ is the maximum temperature and $\mathrm{T}_{\min }$ is minimum temperature.

$$
\text { Average temperature }=\frac{\stackrel{\infty}{\dot{a}} \mathrm{~T}_{\mathrm{i}}}{\mathrm{V}}
$$

where, $T_{i}$ is the temperature for every grid of heated materials.

\section{RESULTS AND DISCUSSION}

The models with different vessel wall sizes and properties were calculated and the following research reports in detail their results during heating.

According to simulation results, the maximum and minimum value of the temperature were recorded during the microwave heating process. Finally, the uniformity of the temperature were calculated by the formula (1) and (2). The results from different vessel wall sizes and properties for the temperature are listed in Tables 3 and 4.

TABLE-3

RESULTS OF THE TEMPERATURE DISTRIBUTION UNDER DIFFERENT VESSEL WALL SIZES

\begin{tabular}{ccccc}
\hline $\begin{array}{c}\text { Thickness of } \\
\text { vessel wall: } \\
\mathrm{d}(\mathrm{m})\end{array}$ & $\begin{array}{c}\mathrm{T}_{\max } \\
(\mathrm{K})\end{array}$ & $\begin{array}{c}\mathrm{T}_{\min } \\
(\mathrm{K})\end{array}$ & $\begin{array}{c}\text { Average } \\
\text { temperature: } \\
\mathrm{T}_{\text {avg }}\left(\mathrm{K} / \mathrm{m}^{3}\right)\end{array}$ & $\begin{array}{c}\text { Temperature } \\
\text { uniformity }\end{array}$ \\
\hline $0.005 \mathrm{~m}$ & 342.201 & 297.368 & 319.256 & 0.362 \\
$0.010 \mathrm{~m}$ & 326.366 & 299.240 & 312.654 & 0.288 \\
$0.020 \mathrm{~m}$ & 312.138 & 299.792 & 305.982 & 0.199 \\
$0.040 \mathrm{~m}$ & 306.806 & 302.275 & 304.858 & 0.122 \\
\hline
\end{tabular}

\section{TABLE-4}

RESULTS OF THE TEMPERATURE DISTRIBUTION UNDER

\begin{tabular}{|c|c|c|c|c|}
\hline $\begin{array}{l}\text { Dielectric vessel } \\
\text { wall }\end{array}$ & $\mathrm{T}_{\max }(\mathrm{K})$ & $\mathrm{T}_{\min }(\mathrm{K})$ & $\begin{array}{c}\text { Average } \\
\text { temperature: } \\
\mathrm{T}_{\mathrm{avg}}\left(\mathrm{K} / \mathrm{m}^{3}\right)\end{array}$ & $\begin{array}{l}\text { Temperature } \\
\text { uniformity }\end{array}$ \\
\hline $\begin{array}{l}\text { Without Dielectric } \\
\text { vessel wall }\end{array}$ & 567.321 & 90.110 & 328.458 & 0.917 \\
\hline $\begin{array}{l}\text { One kind of die- } \\
\text { lectric vessel wall }\end{array}$ & 314.758 & 300.494 & 307.635 & 0.213 \\
\hline $\begin{array}{l}\text { Two kinds of die- } \\
\text { lectric vessel wall }\end{array}$ & 369.195 & 70.029 & 219.597 & 0.900 \\
\hline $\begin{array}{l}\text { Four kinds of di- } \\
\text { electric vessel wall }\end{array}$ & 308.719 & 301.871 & 305.751 & 0.149 \\
\hline
\end{tabular}
DIFFERENT VESSEL WALL PROPERTIES 
By comparing the data in Tables 3 and 4, one can observed that the effect of heating solvent is desired using different vessel wall material and sizes and especially when the thickness of vessel wall is $0.04 \mathrm{~m}$ or the vessel wall is made of four kinds of dielectric vessel wall, the maximum is almost equal to minimum and the temperature uniformity is lowest and the effect of heating solvent is best. From above, it is obvious that the temperature uniformities were influenced by size of vessel wall, the uniformity of temperature can be highly improved by changing the thickness and property of vessel wall.

\section{Conclusion}

By calculation and analysis, the configurations with different thickness and property of walls are integrally compared in the uniformity of temperature field. When the temperature uniformity of non-polar solvent is not obvious during microwave heating, it can improve significantly the uniformity of temperature by changing the thickness and property of vessel wall.

\section{ACKNOWLEDGEMENTS}

This project was supported by National Science Foundation of China (No. 61001019) and Sichuan Province Science supported planning project of China (2011GZ0222).

\section{REFERENCES}

1. A.C. Metaxas, Foundations of Electroheat Chicester, UK, John Wiley \& Sons (1996).

2. Dielectric Heating for Industrial Processes, U.I.E.-Dielectric Heating Working Group, Paris (1992).

3. D. Obermayer, B. Gutmann and C.O. Kappe, Angew. Chem. Int. Ed., 48, 8321 (2009).

4. For the Application of $\mathrm{SiC}$ in Microtiter Plates, see: (a) M. Damm and C.O. Kappe, J. Comb. Chem., 11, 460 (2009); (b) M. Damm and C.O. Kappe, Mol. Div., 13, 529 (2009).

5. G.B. Kumbhar and S.V. Kulkarni, Int. J. Comp. Math. Elect. Electron. Eng., 26, 489 (2007).

6. C. Petrescu and L. Ferariu, Proc. World Acad. Sci.: Engineering and Technology, 30, 1307 (2008).

7. Higher Education Press: Physical and Chemical Experiment (ver. 2nd), China, 264 (1989). 